\title{
Strength Comparison of Accelerated Cured and Normal Cured Fly-Ash Based Concrete
}

\author{
MUHAMMAD ADIL KHAN*, ASJAD JAVED*, AND MAHBOOB ALI CHOUDHRY*
}

RECEIVED ON 28.02.2018, ACCEPTED ON 30.04.2018

\begin{abstract}
The most important property of concrete is its compressive strength, which is carried out after 28-days of proper curing of concrete. This test is affected by other factors like the condition of curing, water to cement ratio, method of transportation, handling of the concrete, extent of vibrations and quality of the ingredients of mix proportion.

This research study is an attempt to develop a simple mathematical model, by using linear regression analysis to estimate the 28-day $f_{c}$ ' (Compressive Strength) of concrete from the test results carried out at early age. This simple linear equation develops a relationship of 28.5 hours. These results show that most of the predicted values of compressive strength, calculated via equations, lie within permissible range difference for compressive strength achieved by experimental method, which is clear indication of credibility of the equations obtained for compressive strength at different age of concrete. The results show that compressive strength of concrete increases with the increase in content of FA (Fly Ash) upto 30\% replacement, and the compressive strength of the concrete starts decreasing beyond $30 \%$ FA substitution. This argument is totally in line with all the literature carried out for this research.
\end{abstract}

Key Words: Compressive Strength, Accelerated Curing, Fly Ash, Concrete, Regression Analysis.

\section{INTRODUCTION}

$\mathrm{T}$

This research is basically an attempt of making a model to develop a relationship between concrete strength and its maturity which could be expressed with a simple mathematical model. The traditional way of determining the strength of concrete is to test moist-cured cylinders at $23^{\circ} \mathrm{C}$ after 28 -days of casting. Sometimes even placement for different areas up to rate of $400 \mathrm{yd}^{3} /$ hour. large structures might get completed even before the 28-days strength. By depending on the test results in order to be sure that proper strength and quality of concrete is satisfied, there is a chance that noticeable quantity of inferior concrete might have been placed before the detection. After the test results, it might not be possible to substitute the inferior quality of concrete without damaging the acceptable quality of concrete in the structure. The cost increase due to this misshape is a consequence of this practice. The 7-days strength of cylinder is not the

Authors E-Mail: (adee.uol@gmail.com, laeeque.ahboob@ce.uol.edu.pk)

* Department of Civil Engineering, The University of Lahore, Lahore.

This is an open access article published by Mehran University Research Journal of Engineering and Technology, Jamshoro under the CC by 4.0 International License. 
solution due to unreliable result for the 28-days strength prediction. Besides, even 7-days wait for the test results is a large amount of time to waste in the modern fast construction era. This fact is evident that the compressive strength of concrete is important in today's concrete construction industry [1-2]. The need to be able to predict the 28-days strength of concrete at early age is influenced by the following factors:

(1) The rush and tight schedule of construction in the modern fast and machined world.

(2) Quality control issue is to be observed strictly via testing.

(3) To be able to know that the quality of concrete for the said project is suitable even before 28 days testing.

(4) To have safety factor in terms of time in case of any misshape regarding strength.

To be able to apply the service loads on the structure prior to the said schedule.

Hydration rate is basically the factor which affects the rate of gaining strength of concrete. Hydration itself is affected by the temperature of surrounding. We can rush the strength gain at early age and then we can relate it to the 28-days compressive strength through proper trend lines and calibration curves. For the accelerated curing of concrete, different methods and techniques have been classified, such as maturity methods, curing in oven, curing in heated water and expanded polystyrene molds method [3-4].

This research work is primarily focused on the study of relation, developed between accelerated curing strength at 28.5 hours (as described by ASTM C 684, 3.5 hour accelerated curing at $100^{\circ} \mathrm{C}$ after normal curing of 23 hours at $21^{\circ} \mathrm{C}$ ) with compressive strength obtained after normal curing of 7, 14, 21 and 28-days of concrete, casted with blended cement.

\section{LITERATURE REVIEW}

Keith et. al. [5] did a research on Prevention of Corrosion in Concrete Using FA Concrete Mixes. They concluded that, FA prevents corrosion in concrete through its extra power with $\mathrm{CO}_{2}$ and its natural pozzolanic properties. FA made the concrete denser and hence made it less permeable and in order to prevent water reaching the steel in reinforced concrete and hence the corrosion is prevented.

A research was carried out by Ozkul [6] on efficiency of accelerated curing in concrete. He used two different but standardized accelerated curing methods. First method was water method and second was boiling water method. Natural and most widely used pozzolan of Turkey was used in concrete. Water reducing admixture, as per ASTM C496, was also used in concrete. And the normal 28-days curing result was compared with accelerated curing result. Linear regression was used to obtain the relationship. The difference was found lesser in boiling water method as compared to warm water method.

Kheder et. al. [7] carried a research on developing a mathematical predictive model for 7 and 28-days compressive strength of cement within 24 hours. The concept of using the early strength to predict the later age strength for Portland cement was used for the first time. They used 50 different cement brands for their research. Out of which they made 450 cement mortar cubes. The cements were produced by 9 different cement companies. They followed British Standard BS-1881 for their research. The quite extensive research almost covered all the aspects of cement properties. 
Viviani et. al. [8] carried out a research on prediction of concrete strength in 3-days. This research presented efficient and simple procedure for concrete strength prediction. The deformation of concrete at early age and the temperature variations formed the basis of a procedure known as Equivalency Points which was used as a parameter for indication of equivalent degree of reaction. They used maturity method to predict the strength of concrete.

Hakim et. al. [9] carried out a research on the application of ANN (Artificial Neural Network) to high strength concrete for its early strength prediction. This research became more complicated due the presence of many several parameters. Janusz Kasperkiewicz collected 368 different mix design data from Institute of Fundamental Technology Research of Poland's Laboratories. All this data was analyzed for early strength prediction through ANN. The error in their predicted values turned out to be $12.63 \%$ as per the available literature.

Shrivastava and and Bajaj [10] carried out a research on Performance of High FA Concrete in Pavement Design. They varied the fly ash content from $0-60 \%$ in concrete which was to be used in pavement design. They concluded that with the increase in FA content, the plastic nature of material decreases and flow index also decreases. This shows that the shear strength of soil increases with the increase of FA content. The bleeding of concrete goes on decreasing with the increase in FA content and as well as the compressive strength shows increased up till 50\% replacement. The increase of FA decreased the expansion of soil and hence made it more suitable for sub-grade and sub-base. The FA based concrete was more cost effective than normal concrete. Also it showed an increase in the values of modulus of rigidity, toughness and elasticity with increased FA content.
Haniron and Tomas [11] worked on Analysis of FA Cement Concrete for Road Construction. They concluded that up to $30 \%$ of FA replacement showed superior performance of concrete for road construction. They further concluded that the use of FA increases the strength of concrete. The use of FA helps the concrete to gain its maximum strength faster. And FA can be effective in concrete road pavement.

Soman and Sobha [12], studied Strength and Behavior of HVFAC (High Volume Fly Ash Concrete). They made replacement with FA up to $50 \%$ by mass. They concluded from their research that, workability is directly proportional to FA content. With the replacement level of $50 \%$ FA the 7 -day strength got reduced by almost $20 \%$ but 28 -days strength of FA based concrete was greater than the control mix. The ultimate load and first crack load was more for HVFAC beams than normal concrete beams. Also FA based concrete was $24 \%$ cost effective than OPCC (Oakville Parent-Child Centre).

\section{MATERIALS AND METHODOLOGY}

Materials used in this research are listed as follow:

\subsection{Natural Coarse Aggregate (Margalla Crush)}

Maximum aggregate size used is $19 \mathrm{~mm}$. The Fineness Modulus was calculated to be 7.32. Specific Gravity was calculated to be 2.5 , and the water absorption of coarse aggregate was found to be $1.1 \%$.

\subsection{Fine Aggregate (Lawrencepur Sand)}

Lawrencepur sand is known for its superior quality and higher strength. The fineness modulus of fine aggregate was calculated to be 2.55 . the bulk specific gravity of fine aggregate was calculated to be 2.78 . and the water absorption for fine aggregate was to found to be $1.2 \%$. 


\subsection{Portable Water (Free from Impurities)}

Ordinary tap water of PH from 6-8, colorless, odorless and free from impurities is used.

\subsection{Ordinary Portland Cement (Maple Leaf Cement)}

Maple Leaf cement is the best available cement in the market which gives the highest compressive strength. It is slightly expensive than the other brands of cement.

\subsection{Fly Ash}

The FA used in this research was of Class-F as per the specification of ASTM C-618. This class is produced from older and harder coal and it contains more iron.

\subsection{Methodology}

For casting of concrete specimens, 6 division of test specimens are casted with ultra-fine FA dosage of $0 \%$ (control specimens), 15, 20, 25, 30 and 35\%, respectively, with compressive strength $28 \mathrm{MPa}$. A total of 15 specimens are casted for each variation of FA and tested at the age of 28.5 hours (accelerated curing), 7, 14, 21 and 28 days. Hence, 90 cylinders are casted and tested in this phase. Detail is shown in Table 1 and Fig. 1.
Concrete mix design was carried out after material testing, the mix design ratio, and the water to cement ratio was found to be:

Mix Design Ratio $=1: 1.5: 2.5$

Water to Cement Ratio $=0.502$

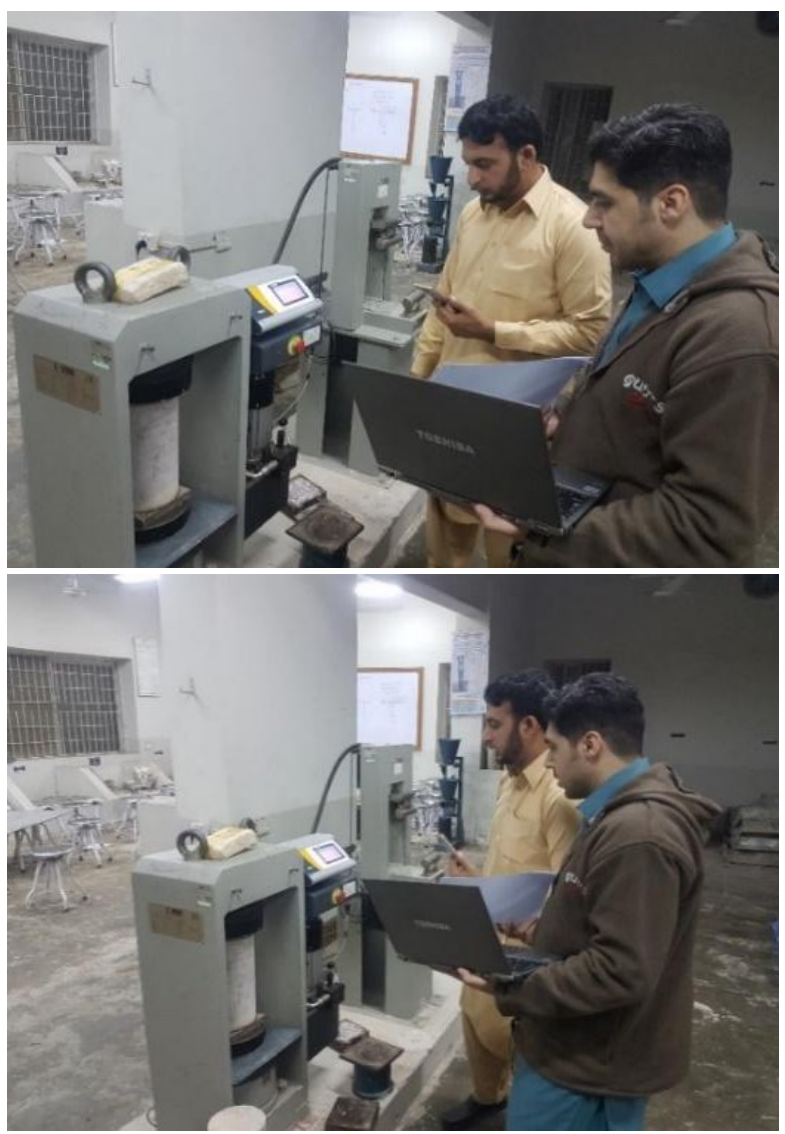

FIG. 1. CARRYING OUT COMPRESSION TEST

TABLE 1. DETAIL OF CYLINDER SPECIMENS

\begin{tabular}{|c|c|c|c|c|c|c|}
\hline Age of Concrete & \multirow{2}{*}{28.5 (Hours) } & \multirow{2}{*}{ 7-Days } & \multirow{2}{*}{ 14-Days } & \multirow{2}{*}{ 21-Days } & \multirow{2}{*}{ 28-Days } & \multirow{2}{*}{ Total pecimens } \\
\hline $\begin{array}{c}\text { Replacement } \\
\text { Level of Fly Ash (\%) }\end{array}$ & & & & & & \\
\hline 0 & 3 & 3 & 3 & 3 & 3 & 15 \\
\hline 15 & 3 & 3 & 3 & 3 & 3 & 15 \\
\hline 20 & 3 & 3 & 3 & 3 & 3 & 15 \\
\hline 25 & 3 & 3 & 3 & 3 & 3 & 15 \\
\hline 30 & 3 & 3 & 3 & 3 & 3 & 15 \\
\hline 35 & 3 & 3 & 3 & 3 & 3 & 15 \\
\hline Total Number of Cylinders & 18 & 18 & 18 & 18 & 18 & $=90$ \\
\hline
\end{tabular}

Mehran University Research Journal of Engineering \& Technology, Volume 39, No. 1, January, 2020 [p-ISSN: 0254-7821, e-ISSN: 2413-7219] 


\section{RESULTS AND DISCUSSION}

The average of each day's compressive strength is mentioned in Table 2.

Table 2 clearly shows that the optimum value of FA substitution is $30 \%$. Any further increase in percentage of FA replacement shows a decrease in strength of concrete. This argument is totally in line with the literature review of the research work. The reason for strength reduction beyond this percentage may be attributed to the fact of lower Pozzolanic activity in concrete due to absence of cement percentage. The results for 28.5 hours (accelerated cured) tests and for 28-days (Normal Cured) tests are graphically shown in Figs. 2-3.

TABLE 2. RESULTS OF COMPRESSIVE STRENGTH TEST

\begin{tabular}{|c|c|c|c|c|c|c|}
\hline No. & $\begin{array}{c}\text { Fly-Ash } \\
(\%)\end{array}$ & $\begin{array}{c}28.5 \text { Hours Test } \\
\text { Result } \\
(\mathrm{MPa})\end{array}$ & $\begin{array}{c}\text { 7-Days Test } \\
\text { Results } \\
(\mathrm{MPa})\end{array}$ & $\begin{array}{c}\text { 14-Days Test } \\
\text { Results } \\
(\mathrm{MPa})\end{array}$ & $\begin{array}{c}21 \text {-Days Test } \\
\text { Results } \\
(\mathrm{MPa})\end{array}$ & $\begin{array}{c}28 \text {-Days Test } \\
\text { Results } \\
(\mathrm{MPa})\end{array}$ \\
\hline 1. & 0 & 14.52 & 20.68 & 21.55 & 22.06 & 29.41 \\
\hline 2. & 15 & 18.36 & 16.45 & 24.87 & 25.19 & 28.21 \\
\hline 3. & 20 & 19.97 & 17.95 & 25.82 & 26.65 & 29.35 \\
\hline 4. & 25 & 20.33 & 21.81 & 26.21 & 28.03 & 30.37 \\
\hline 5. & 30 & 22.77 & 22.73 & 26.96 & 28.63 & 31.95 \\
\hline 6. & 35 & 20.53 & 21.06 & 25.97 & 27.75 & 31.39 \\
\hline
\end{tabular}

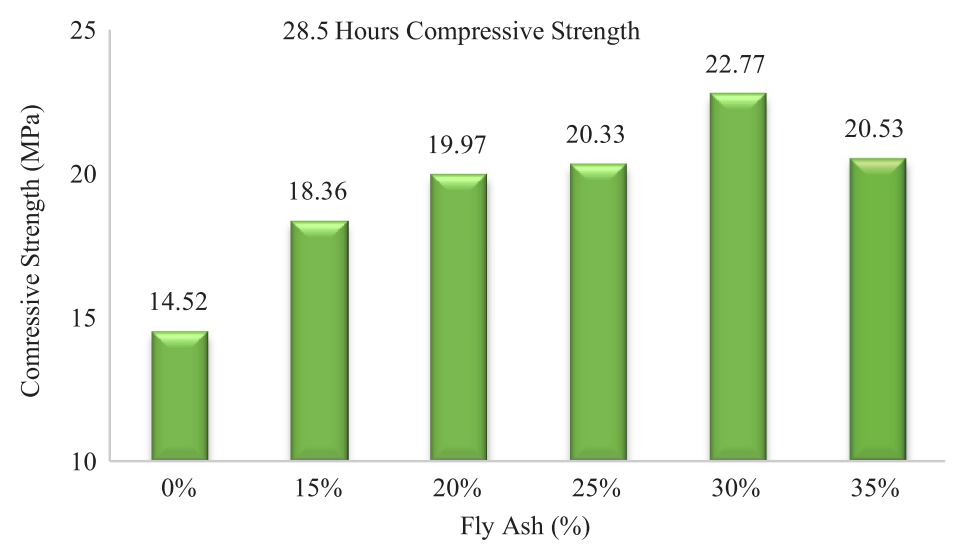

FIG. 2. COMPRESSIVE STRENGTH OF 28.5 HRS TEST RESULT WITH INCREASE OF FLY ASH

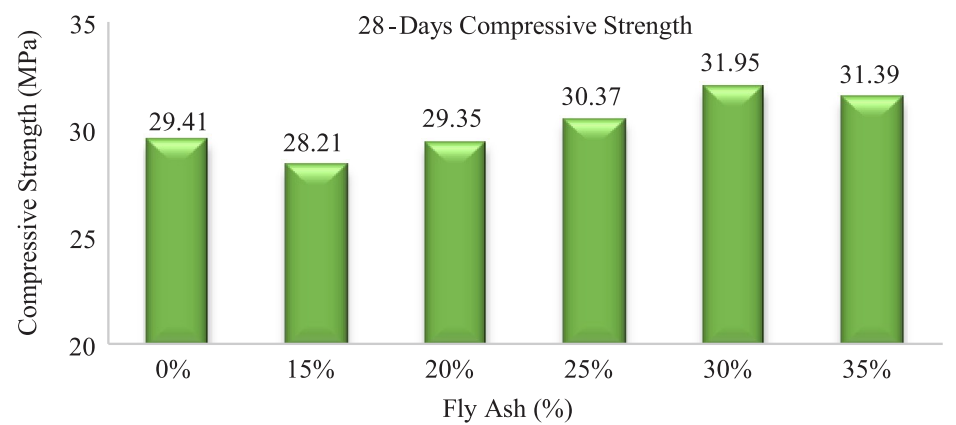

FIG. 3. COMPRESSIVE STRENGTH OF 28-DAYS TEST RESULT WITH INCREASE OF FLY ASH 
The incorporation of FA in the concrete affects its compressive strength. Each variation of FA from results shown in Table 2 were compared with the control sample's test for each day. And the percentage variation is listed in Table 3 . The percentage variation is calculated by the Equation (1).

$\left|\frac{(\text { Large Value })-(\text { Smallar Value })}{(\text { Large Value })} \times 100\right|$

\subsection{Linear Regression}

Linear regression analysis is an attempt to develop a model which shows a relationship between two variables. It fits a linear equation into the obtained data. A scatter plot is helpful in plotting the data and then a linear equation can be developed for the said data by introducing a trend line in the data. The linear equation consists of two variables, one is said to be explanatory variable and the other is called dependent variable. The strength of linear equation is determined by a correlation coefficient, which is a numerical value, ranging between -1 and 1.

In this research, the number of days is explanatory variable and 7,14, 21 and 28-days compressive strength is dependent variables. A linear equation is for a straight line and is stated as $\mathrm{Y}=\mathrm{mX}+\mathrm{c}$, where $\mathrm{Y}$ is the dependent variable and $\mathrm{X}$ is the explanatory variable, " $\mathrm{m}$ " denotes the gradient of the line and " $c$ " is the $y$-intercept when the value of " $x$ " is zero.

\subsection{R-Squared}

It is the measure of how close the regression equation is to the data observed. Statistically it is also known as coefficient of determination. This value varies between $0-100 \%$. The closer this value to $100 \%$ the most accurate will be the results obtained by putting the data into it. It can simply be stated that higher value of R-squared means that model fits the data more accurately. Usually any value more than $80 \%$ is acceptable in a research. It means that there is an $80 \%$ chance/probability, that the model would give nearly $80 \%$ accurate value to the data.

\subsection{Linear Regression Analysis}

Regression analysis carried out for the data observed from the compressive strength values shown in Table 2 has been done via developing graphs (scatter plots). The line introduced in the graph is trend line which is actually the mathematical model, which was the core purpose of this research. The mathematical model is expressed as a linear equation. And the R-Squared value shows the accuracy of the model developed. The y-axis of graph denotes the strength in MPa for a specific value of fly ash percentage. Whereas, $\mathrm{x}$-axis denotes the day on which compressive test was performed.

TABLE 3. COMPARISON OF COMPRESSIVE STRENGTH

\begin{tabular}{|c|c|c|c|c|c|c|}
\hline No. & $\begin{array}{c}\text { Fly-Ash } \\
(\%)\end{array}$ & $\begin{array}{c}28.5 \text { Hours Test } \\
\text { Result } \\
(\mathrm{MPa})\end{array}$ & $\begin{array}{c}\text { 7-Days Test } \\
\text { Results } \\
(\mathrm{MPa})\end{array}$ & $\begin{array}{c}\text { 14-Days Test } \\
\text { Results } \\
(\mathrm{MPa})\end{array}$ & $\begin{array}{c}\text { 21-Days Test } \\
\text { Results } \\
(\mathrm{MPa})\end{array}$ & $\begin{array}{c}\text { 28-Days Test } \\
\text { Results } \\
(\mathrm{MPa})\end{array}$ \\
\hline 1. & 0 & 0.0 & 0.0 & 0.0 & 0.0 & 0.0 \\
\hline 2. & 15 & 20.92 & 20.45 & 13.5 & 12.43 & 4.08 \\
\hline 3. & 20 & 27.29 & 13.20 & 16.54 & 17.22 & 0.20 \\
\hline 4. & 25 & 28.58 & 5.18 & 17.78 & 21.30 & 3.16 \\
\hline 5. & 30 & 36.32 & 9.02 & 20.07 & 22.95 & 7.95 \\
\hline 6. & 35 & 29.27 & 1.80 & 17.02 & 20.50 & 6.31 \\
\hline
\end{tabular}

Mehran University Research Journal of Engineering \& Technology, Volume 39, No. 1, January, 2020 [p-ISSN: 0254-7821, e-ISSN: 2413-7219] 
For each variation of FA, a separate graph has been made, and a separate model has been developed. These models would be predicting the compressive strength of $3,7,14$, 21 and 28-days for a specific FA substitution. The regression analysis is shown in Fig. 4.

\subsection{Linear Regression Equations}

The mathematical equations obtained after carrying out regression analysis are listed in Table 4.

\subsection{Difference between Actual and Predicted Values}

The mathematical models obtained after carrying the regression analysis are checked for predicting the values of the compressive strength. These values with the percentage variation from original results are listed in Tables 5-6.

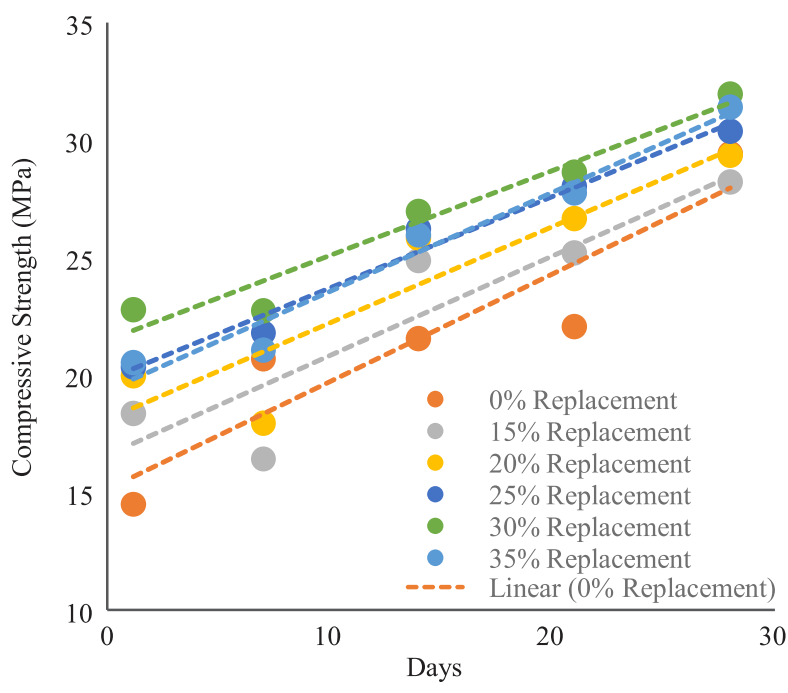

FIG. 4. LINEAR REGRESSION ANALYSIS

TABLE 4. LINEAR REGRESSION EQUATIONS FOR DIFFERENT FLY ASH PERCENTAGE

\begin{tabular}{|c|c|c|c|}
\hline No. & $\begin{array}{c}\text { Fly Ash } \\
(\%)\end{array}$ & Equation for Strength Prediction & $* \mathrm{R}^{2}$ Value \\
\hline 1. & 0 & $\mathrm{y}=0.4579 \mathrm{x}+15.125$ & 0.856 \\
\hline 2. & 15 & $\mathrm{y}=0.4238 \mathrm{x}+16.583$ & 0.829 \\
\hline 3. & 20 & $\mathrm{y}=0.4095 \mathrm{x}+18.118$ & 0.837 \\
\hline 4. & 25 & $\mathrm{y}=0.3891 \mathrm{x}+19.811$ & 0.978 \\
\hline 5. & 30 & $\mathrm{y}=0.3609 \mathrm{x}+21.469$ & 0.967 \\
\hline 6. & 35 & $\mathrm{y}=0.4219 \mathrm{x}+19.334$ & \\
\hline \multicolumn{2}{r|}{} \\
\hline \multicolumn{2}{r|}{ (i.e. in this research it is the compressive strength of concrete). In these equations "x" represents the day on which the compressive } \\
\end{tabular}

TABLE 5. PERCENTAGE VARIATION IN 28.5 HRS COMPRESSIVE STRENGTH

\begin{tabular}{|c|c|c|c|c|}
\hline \multirow{2}{*}{ No. } & \multirow{2}{*}{ Fly Ash (\%) } & \multicolumn{3}{|c|}{ Compressive Strength (MPa) } \\
\cline { 3 - 5 } & & \multicolumn{3}{|c|}{28.5 hours } \\
\cline { 3 - 5 } & & Actual & Predicted & $\begin{array}{c}\text { Variation } \\
\text { (\%) }\end{array}$ \\
\hline 1. & 0 & 14.52 & 15.67 & 7.3 \\
\hline 2. & 15 & 18.36 & 17.09 & 6.9 \\
\hline 3. & 20 & 19.97 & 18.60 & 6.9 \\
\hline 4. & 25 & 20.33 & 20.27 & 0.3 \\
\hline 5. & 30 & 22.77 & 21.90 & 3.8 \\
\hline 6. & 35 & 20.53 & 19.84 & 3.4 \\
\hline
\end{tabular}

Mehran University Research Journal of Engineering \& Technology, Volume 39, No. 1, January, 2020 [p-ISSN: 0254-7821, e-ISSN: 2413-7219] 
TABLE 6. PERCENTAGE VARIATION IN 28-DAYS COMPRESSIVE STRENGTH

\begin{tabular}{|c|c|c|c|c|}
\hline \multirow{2}{*}{ No. } & \multirow{2}{*}{$\begin{array}{c}\text { Fly Ash } \\
(\%)\end{array}$} & \multicolumn{3}{|c|}{ Compressive Strength (MPa) } \\
\cline { 3 - 5 } & & & \multicolumn{2}{|c|}{28 Days } \\
\cline { 3 - 5 } & & Actual & Predicted & $\begin{array}{c}\text { Variation } \\
(\%)\end{array}$ \\
\hline 1. & 0 & 29.41 & 27.95 & 4.9 \\
\hline 2. & 15 & 28.21 & 28.45 & 0.8 \\
\hline 3. & 20 & 29.35 & 29.58 & 1.1 \\
\hline 4. & 25 & 30.37 & 30.71 & 1.2 \\
\hline 5. & 30 & 31.95 & 31.57 & 0.8 \\
\hline 6. & 35 & 31.39 & 31.15 & 0.8 \\
\hline
\end{tabular}

\section{CONCLUSIONS}

This research aimed at developing a strength prediction model for concrete. This would help us in saving time and delay of 28-days in order to find the compressive strength of concrete after casting. Furthermore, FA has been used as partial replacement of cement, which highly reduced the cost of concrete. The ultimate outcome of this research is that we would now be able to know the 28-days $\mathrm{f}_{\mathrm{c}}{ }^{\prime}$ of concrete by using the regression models used for this purpose, and being able to produce an economical concrete by incorporating FA into it.

Results show that optimum value of FA that can be substituted with cement is $30 \%$. This argument is totally in line with the literature review of this research, as 35\% FA substitution is again decreasing the strength of concrete.

Furthermore, the regression models have been further verified through graphs and tables for each day strength, and it is found that all the variation in the predicted values is in permissible zone. The authenticity of these equations has been clearly explained by the $\mathrm{R}^{2}$ values for each equation, which in each case, is more than $80 \%$.
It is to be clearly noted that each regression model is valid for a certain percentage of FA. These equations cannot be used as generalized equations for any type of concrete or any percentage of FA. The equation can be used as such that the user only needs to put any number of day as value of " $x$ " and will get the result of the equation as " $y$ ", which is the compressive strength for that day. In general, now any user would be able to predict the strength of concrete with a specific amount of fly ash substitution in just a few minutes due to the availability of these regression models.

The results obtained after carrying out this research indicate that when FA is substituted with cement, the strength of the concrete increases. This increase in strength is economical as compared to normal concrete produced with $100 \%$ of cement.

Increase in 28.5 hours compressive strength with $30 \%$ FA substitution is almost $36 \%$. Increase in 7-days compressive strength with $30 \%$ FA substitution is almost $9 \%$. Increase in 14-days compressive strength with $30 \%$ FA substitution is almost $20 \%$. Increase in 21-days compressive strength with $30 \%$ FA substitution is almost 
$23 \%$. Increase in 28 -days compressive strength with $30 \%$ FA substitution is almost $8 \%$. In each case, the compressive strength started decreasing when the FA substitution increased to $35 \%$.

Minimum $\mathrm{R}^{2}$ value obtained for regression model has a probability of $83 \%$ to give a value closer to the actual value. This means that only $17 \%$ chance of predicted value variation from actual value can occur, and the maximum value of $\mathrm{R}^{2}$ obtained has a probability of $98 \%$, which means that the chance of predicted value to be different from actual value is only $2 \%$. In both these extreme condition cases, the regression models fit the data by minimum of $83 \%$ and maximum of $98 \%$.

\section{RECOMMENDATIONS}

Stated below are some of the recommendations to be carried out in further studies by the researchers.

(1) These equations are not verified whether or not they can be used to predict the strength of High strength FA based concrete. Hence further study is needed on High Strength FA Based concrete to confirm the chance of any modification in these equations.

(2) Further study is required to establish a direct relationship of accelerated cured and normally cured FA based concrete.

(3) Further testing and more study is needed on FA based concrete to indicate its characteristics and strength. The testing includes flexural strength, modulus of elasticity test, tensile strength and fatigue strength etc.
(4) It is recommended that these equations may not be applied to other size of samples without carrying out research with the same variation of FA but in different sample sizes.

(5) The study of FA in concrete shows the increase in durability of concrete, it needs to be studied in further studies for long term testing and properties like water absorption and density.

(6) More laboratory testing and investigation needs to be carried out for determining the shrinkage and creep characteristics of FA based concrete.

(7) The cost saved due to FA substitution in any mega project can be used to investigate if fiber reinforced FA based concrete can serve as high strength concrete with almost same budget.

(8) Use of admixtures like self-curing, selfcompacting and super plasticizers in FA based concrete is recommended with accelerated curing.

(9) Use of high percentage of FA is recommended to further increase the strength of concrete with the addition of admixtures, keeping the economy factor intact.

\section{ACKNOWLEDGEMENT}

This research work has been carried out in the Department of Civil Engineering, The University of Lahore, Lahore, Pakistan. 


\section{REFERENCES}

Dias, W.P.S., and Pooliyadda, S.P., "Neural Networks for Predicting Properties of Concretes with Admixtures", Construction and Building Materials, Volume 15, No. 7, pp. 371-379, October, 2001.

Ni, H-G., and Wang, J-Z., "Prediction of Compressive Strength of Concrete by Neural Networks", Cement and Concrete Research, Volume 30, No. 8, pp. 1245-1250, August, 2000.

[3] Torkey, A.A., "Accelerated Strength for Quality Control of Mortar and Concrete", M.Sc. Thesis, Faculty of Engineering, Cairo University, 1980.

Kheder, G.F., Al-Gabban A.M., and Suhad, M.A., "Mathematical Model for The Prediction of Cement Compressive Strength at the Ages of 7 and 28 Days Within 24 Hours", Materials and Structure, Volume 36, pp. 693-701, 2003.

Keith, B., and Tarunjit, S.B., "Prevention of Corrosion in Concrete Using Fly Ash Concrete Mixes", NBS Special Publication, Volume 511, No. 1, [SD Stock No. SN-00301926-7], 2000.

Ozkul, M.H., "Efficiency of Accelerated Curing in Concrete ", Cement and Concrete Research, Volume 31, pp. 1351-1357, 2001.
[7] Kheder, G.F., Al-Gabban, A.M., and Abid, S.M., "Mathematical Model for the Prediction of Cement Compressive Strength at the Ages of 7 and 28 Days within 24 Hours", Materials and Structures, Volume 36, pp. $693701,2003$.

[8] Viviani, M., Glisic, B., Scrivener, K.L., and Smith, I.F.C., "Equivalency Points: Predicting Concrete Compressive Strength Evolution in Three Days", Cement and Concrete Research, Volume 38, pp. 1070-1078, 2008.

[9] Hakim, S.J., Seyed, N.J., and Jaafar, M.S., “Application of Artificial Neural Networks to Predict Compressive Strength of High Strength Concrete", International Journal of the Physical Sciences, Volume 6, pp. 975 $981,2011$.

[10] Shrivastava, Y., and Bajaj, K., "Performance of Fly Ash and High Volume of Fly Ash Concrete in Pavement Design", IACSIT Coimbatore Conferences, IPCSIT, Volume 28, Singapore, 2012.

[11] Haniron, J., and Tomas, U., “Analysis of Fly Ash Cement Concrete for Road Construction", International Journal of Advanced Science and Technology, Volume 60, pp. 33-44, 2013.

[12] Soman, M., and Sobha, K., "Strength and Behaviour of High Volume Fly Ash Concrete", International Journal of Innovative Research in Science, Engineering and Technology, Volume 3, No. 5, May, 2014. 